\title{
Accommodation and Health Costs of Deinstitutionalized People with Mental Illness Living in Residential Services in Brazil
}

\author{
Denise Razzouk ${ }^{1}$
}

Published online: 30 April 2018

(C) The Author(s) 2018

\begin{abstract}
Background Health costs are the main hindrances for expanding community mental health services. Exploring patient profiles and cost predictors may be useful for optimising financial resources. However, the deinstitutionalisation process may burden health budgets in terms of supporting multiple community services based on varying levels of need.

Objective This study assessed accommodation and health service costs, quality of life and clinical and psychosocial profiles among individuals receiving mental healthcare through residential services. Specific accommodation cost predictors were also verified.

Methods Health costs were assessed from the perspective of a public health provider using a microcosting bottom-up approach at 20 residential services in São Paulo, Brazil. Instruments used to assess health costs and patient profiles included the Brazilian version of the Client Socio-demographic and Service Receipt Inventory (CSSRI), the Mini International Neuropsychiatric Interview (MINI), the Clinical Global Impression-Severity Scale (CGI-S), the Independent Living Skills Survey (ILLS), the Social Behaviour Scale (SBS) and the Quality of Life Scale (QLS).

Results One hundred and forty-seven residents, predominantly experiencing psychotic disorders, were interviewed.
\end{abstract}

Electronic supplementary material The online version of this article (https://doi.org/10.1007/s41669-018-0078-z) contains supplementary material, which is available to authorized users.

Denise Razzouk

drazzouk@gmail.com

1 Department of Psychiatry, Centro de Economia da Saúde Mental, Universidade Federal de São Paulo, Rua Borges Lagoa 570, Vila Clementino, São Paulo 04038-000, Brazil
The geographical region and length of time spent living in residential services or in a psychiatric hospital predicted $66 \%$ of the variance in accommodation costs. The CGI-S and ILLS scores and years of education explained 52.7\% of the variance in quality of life.

Conclusion Accommodation costs were not driven by patient profile variables, while region and time spent in a hospital or in residential services were the main cost predictors. Semi-staffed homes may be an alternative for resource optimisation among individuals with mild impairment, particularly if strategies for psychosocial rehabilitation and improving quality of life are implemented.

\section{Key Points for Decision Makers}

Fully staffed accommodation costs correspond to the largest proportion of costs associated with mental healthcare packages for deinstitutionalised psychiatric patients.

Residential service costs may depend on the region where services are located, and these costs can vary according to the length of time individuals are using mental health services (residential or psychiatric hospital).

There is a need to offer different types of residential services according to different levels of psychiatric and psychosocial impairments. Poor quality of life is related to low independent living skills and greater psychiatric symptom severity. Implementation of psychosocial rehabilitation strategies may allow residents to gain autonomy and live with fewer staff support provisions within cost-saving homes. 


\section{Introduction}

The goals of psychiatric deinstitutionalisation are driven by improving quality of life, guaranteeing citizenship and promoting social inclusion for people with mental disorders. In this regard, residential services have been the core of community mental health; however, organising and financing such services are challenged by cost issues and variable resident needs $[1,2]$. Residential services are houses dispersed in the community with and without 24-h staff support, offering accommodation and support for people with mental illnesses who lack family support, especially when discharged from a psychiatric hospital.

People discharged from long stays at a psychiatric hospital need a combination of services to support their physical health, mental health and social inclusion. However, these services differ with regard to the number of available resources, complexity, staff support, types of interventions and costs [3]. Of particular concern is the cost variability among individuals in the community, which may differ across multiple health and non-health services. This results in challenges to health service planning [3].

Psychiatric hospitalisation is usually an expensive alternative to care, but community mental health services might not always be a cheaper alternative $[1,4,5]$. There is a lack of consensus on the assessment of service quality and cost effectiveness. Thus, deinstitutionalisation may be as expensive as institutionalisation, depending on the structure and quality of the services delivered [4]. Also, little is known regarding how a patient's needs vary over time and which alternatives to housing support are truly cost saving [6].

A patient's profile is also a significant predictor of accommodation and health service costs within the mental healthcare sector $[3,7,8]$. However, the role of patient profiles has not been confirmed over the long-term $[9,10]$. Residential costs have previously been correlated with younger age, being female, having a paranoid schizophrenia or affective disorder diagnosis, exhibiting aggressive behaviour and having fewer life skills [11]. Additional characteristics include geographic region and service size [12]. Yet, variable correlations are observed between individual patient profiles and accommodation/non-accommodation health service costs [13-15].

Costs and outcomes also vary within the residential service modality $[13,14]$. For instance, living in a residential facility is correlated with improved physical health, better independent living skills and higher use of community resources when compared with independent supported housing (ISH) [14]. Conversely, living in ISH is associated with greater individual autonomy, freedom to make choices, lower participation in social activities, lower integration in the community, higher risk of suffering violence and worse physical and mental health.

While deinstitutionalisation initiatives were started several decades ago within high-income countries, this topic is still relevant for evaluating mental health policies in terms of costs, quality and outcomes [16]. Furthermore, the re-institutionalisation rate [17] of individuals with mental disorders has been growing within some high-income countries. Additionally, the deinstitutionalisation process is still in progress across many low- and middleincome countries [18]. Within developing countries, planning financial resources for scaling-up services is crucial when dealing with scarce resources.

In Brazil, for instance, psychiatric beds reduced from 120,000 to 25,000 between 1990 and 2016. Law number 10216 (enacted in 2001) determined the need for the progressive elimination of psychiatric hospitals in Brazil. In 2005, the Brazilian Ministry of Health reported that 9000 people were living in psychiatric hospitals across the country; of these, three-quarters were in the State of São Paulo. Here, community mental healthcare was implemented toward the end of the 1990s [10], and approximately half of all services were implemented in São Paulo, which currently has a population of 50 million inhabitants. According to the Psychosocial Census in the State of São Paulo in 2014, 4439 people were still living in 53 psychiatric hospitals and waiting for the creation of an additional 554 residential services [19]. Also in 2014, there were 280 residential service locations in Brazil for 2031 patients. Currently, the State of São Paulo has approximately 200 residential services, but this is not enough to deal with the current service demand. The Brazilian mental health system is a complex network of services comprising primary care, outpatient services (referred to as the centre of psychosocial care-'CAPS'; some have psychiatric beds and day hospital intensive care), ambulatory services (for delivering care in psychiatry and other health specialities), psychiatric hospitals, psychiatric beds in general hospitals, first aid care (referred to as 'UPA'; for psychiatry and other health specialities), emergency care in general hospitals and residential services. Minor mental health disorders are treated through primary care services, while individuals with a moderate or severe illness are treated through CAPS. Residential facilities were created to accommodate people discharged from psychiatric hospitals. Each residential service is located close to one CAPS where mental health treatment is delivered [10]. Access to public healthcare is a free, universal and egalitarian right in Brazil. Approximately one-quarter of the population has private health insurance.

In 2008, after a judicial order, the city of São Paulo closed two psychiatric hospitals; all inpatients were discharged into 20 residential services. Up until 2008, there 
was only one residential service in the city, and 19 services were created between 2007 and 2009.

We conducted a study between 2010 and 2012 evaluating the aforementioned patient group discharged from psychiatric hospitals in São Paulo. We specifically examined patients' clinical and psychosocial profiles, treatment, quality of life, autonomy, health service use, and health and accommodation costs. Predictors of accommodation and health costs were also assessed. We predicted that user profiles might be related to accommodation costs, especially among individuals with greater symptom severity. A secondary objective was to compare health service use between mild and moderate/severe psychiatric symptom groups.

\section{Methods}

This cross-sectional study evaluated residents in 20, 24-h staffed residential facilities, each with eight residents, in São Paulo. This study is part of a larger project to evaluate resident profiles and quality of life, residential and health service use and costs, caregivers' perspectives regarding psychosocial rehabilitation, ethnographic observations of residential service structure/function, and estimation of unit costs for mental health services and interventions. Part of this project is described elsewhere [7, 20].

\subsection{Local and Financial Sources for Residential Services}

There are two types of residential services: type I (one caregiver is available on demand) and type II (24-h staffed homes). In São Paulo, only type II services were available during the study period. This modality comprised rented homes dispersed in the community with six to nine laycaregivers within a duty work scheme. Caregivers were responsible for cleaning, cooking, medication dispensing, promoting psychosocial rehabilitation and supporting residents' general needs. These caregivers had different educational and training profiles. Lay caregivers are people with no previous experience in the health service field, and they usually have a secondary education level. Professional mental health caregivers are workers with specific training in the mental health field (e.g. nurse assistants). These services are publicly funded by the Federal Government (20,000.00 Brazilian real [BRL] per service per month), and the remaining expenses are paid by the municipal government. Medications were funded federally and by the State of São Paulo. These services are linked to a public mental health network for specific primary care and general hospitals. Non-health services in the community comprised leisure, sport, workshop and vocational training units.

\subsection{Sample}

All residents who met the following inclusion criteria were invited to participate: deinstitutionalised for at least 6 months; previously lived in a psychiatric hospital for 1 year or more; and able to communicate and answer questions from interviewers.

\subsection{Assessments}

Seven independent trained mental health researchers (psychiatrists and occupational therapists) interviewed the caregivers and residents face-to-face. Instruments used included the Mini International Neuropsychiatric Interview (MINI) [21, 22] for psychiatric diagnoses, the Clinical Global Impression-Severity subscale (CGI-S) to assess symptom severity [21, 23, 24], the Quality of Life Scale (QLS) [25, 26], the Social Behaviour Scale (SBS) [27] and the Independent Living Skills Scale (ILSS) [28]. The Client Socio-Demographic and Service Receipt Inventory (CSSRI) was used to assess health resource use [31]. All assessment tools were translated and validated in Portuguese.

\subsection{Instruments}

\subsubsection{Mini International Neuropsychiatric Interview (MINI)}

A Brazilian version (5.0) of the MINI [21] is a short semistructured diagnostic psychiatric interview developed for use in clinical settings and research in order to assess lifetime and current psychiatric diagnoses according to Diagnostic Manual for Mental Disorders, 4th edition (DSM-IV) and International Classification of Diseases, 10th edition (ICD-10) criteria. The psychometric properties of the Brazilian version of the MINI were considered acceptable in previous studies [21] when compared with the original version (CIDI). Agreement between MINI diagnostics and a panel of psychiatrists was $85 \%$ [21].

\subsubsection{Clinical Global Impression-Severity Scale (CGI-S)}

The Brazilian version of the CGI-S [24] was applied to assess illness severity. The CGI-S score is based on behaviour, global functioning and symptoms over the last 7 days. This scale comprises five dimensions (positive, negative, cognitive, depressive symptoms and global). Scores range from 1 (normal) to 7 (the highest level of severity). 


\subsubsection{Quality of Life Scale (QLS)}

The Brazilian version of the QLS [25] was used to assess each participant's quality of life over the last 3 weeks.

\subsubsection{Independent Living Skills Scale (ILSS)}

The Brazilian version of the ILSS [29] was used to assess functional living skills in domains such as food preparation, diet, health, transportation, self-care, leisure, money management, maintenance and global autonomy. The frequency of behaviours is scored from 'never occurs' (score $0)$ to 'always occurs' (score 4) during the last month. Higher scores indicate better functioning. Data for the ILSS were provided by the caregiver.

\subsubsection{Social Behaviour Scale (SBS)}

The Brazilian version [30] of the SBS is a 21-item scale that covers daily social behaviour over the last month, with information provided by the caregiver. Each item is scored from 0 (normal) to 4 (severe behaviour problem).

\subsection{Health Service Utilization, Socio-Demographic Data and Costs}

The CSSRI [31] is a semi-structured instrument used to assess social and demographic data, accommodation data, detailed information regarding treatment, professional visits, and social and health service utilisation for estimating healthcare costs. The CCSRI was translated into Portuguese and adapted to Brazil's healthcare structure $[32,33]$. Both patients and caregivers provided information for the CSSRI, but caregiver answers were taken as the gold standard when there was disagreement.

\subsection{Estimating Costs}

This study estimated direct health costs (accommodation and non-accommodation) for each resident during the previous month before the interview through a public health provider perspective. Accommodation costs were assessed for 20 residential services covering 160 patients, directly with each service coordinator, using a microcosting bottom-up approach. Cost data were assessed for the following components: rent, equipment, utilities, food, housing supplies, maintenance, transport, overheads and human resources. Non-accommodation costs included all costs incurred due to health system utilisation, including hospital and community services, medication and psychosocial interventions delivered by occupational therapists, psychologists and other health professionals.

\subsection{Unit Costs}

Brazil has a Datasus database showing the reimbursements paid by the Federal Government to states and municipalities. However, this database does not provide the real public health services costs because states and municipalities finance services and treatment with their own budgets. In the present study, the goal was to estimate the direct health costs covering the Federal Government, states and municipalities.

All unit costs for outpatient services were estimated using a top-down approach based on data obtained from health managers from 12 services dispersed across all five regions of São Paulo. All data regarding residential costs were collected and estimated through a microcosting bottom-up approach. Unit costs for medications were obtained from the National Medicine Price Database [34], a government database indicating costs per pill, by city and per year, paid by public health managers. The largest values per pill for São Paulo in 2011 were chosen to estimate all medication costs. All costs were estimated for 2011 because it was the only year where cost data were available.

\subsection{Statistical Analyses}

Descriptive analyses were used for sample characteristics, quality of life, and service and medication use. Health costs were estimated from the sum of accommodation costs (residential care) and health service use and treatment costs (medicines and psychosocial interventions) for each resident who met eligibility criteria from the prior month's interview. Health service use and costs were compared between two groups: normal to mild psychiatric symptoms (CGI-S scores 1-3) and moderate to severe psychiatric symptoms (CGI-S scores 4-7). Multivariate linear regressions were employed to explore two models: one related to accommodation costs as the dependent variable and another exploring quality of life as the dependent variable. The main hypothesis in this study was to verify whether severe psychiatric symptoms were predictors of accommodation costs. In this regard, poor scores in SBS and ILSS scales and the length of time living in the psychiatric hospital might be associated with the severity of psychiatric symptoms and, for this reason, these variables were also analysed in the model. The second model was a secondary analysis to explore whether the quality of life could be predicted by symptom severity.

\section{Results}

One hundred fifty-one individuals met eligibility criteria for the study. Of these, four refused to participate, resulting in a final sample of 147 residents. Psychiatric and 
sociodemographic profiles are described in Table 1. There were no significant differences of resident profiles across the five residential regions (Electronic Supplementary Material). Participants had a mean age of $50.3 \pm 13.2$ years, ranging from 19 to 77 years. The mean length of time living in a residential facility was 3 years, ranging from 2 months to 7 years. Almost $65 \%$ of the sample $(n=96)$ had a CGI-S $\geq 4$, indicating moderate to severe psychiatric symptoms.

Table 2 shows residents' economic and psychosocial characteristics, along with the quality of life. Impairment determined by both the SBS and ILSS scales were present in $59.2 \%(n=89)$ of residents, while $29 \%(n=43)$ only had an impairment with independent living skills; $17 \%$ $(n=11)$ only had impairments with social behaviours. At least one severe social behaviour problem was present in $87 \%$ of the sample. The mean ( \pm standard deviation [SD]) ILSS score per resident was $1.5 \pm 0.9$, suggesting severe impairment in daily skills, while $72 \%$ had significant impairment in autonomy. Quality of life was poor in $90 \%$ of the sample, especially in terms of social withdrawal, aimless inactivity, lack of motivation and no sense of purpose. SBS, quality of life, ILSS and length of time living in a psychiatric hospital were correlated with CGI-S; thus, these variables were addressed in the multivariate analyses (see Electronic Supplementary Material).

Table 3 shows accommodation and health service use and costs according to symptom severity. Of note, $<22 \%$ of the mild group and $25 \%$ of the severe group had at least one monthly contact with professionals delivering psychosocial interventions (psychologists and occupational therapists).

The mean $( \pm \mathrm{SD})$ number of psychotropics in regular use was $3.20 \pm 1.25$ and $3.47 \pm 1.46$ for the mild and moderate/severe group, respectively. Antipsychotics were the most used medication $(n=134)$. The combination of two or more antipsychotics (polytherapy) was 39.5 and $43 \%$ in the mild and moderate/severe group, respectively (Electronic Supplementary Material). Similarly, the average $( \pm \mathrm{SD})$ cost of antipsychotics per day was BRL $7.96 \pm 14.57$ and BRL $7.10 \pm 11.97$ for the mild and moderate/severe group, respectively. Overall, the average $( \pm \mathrm{SD})$ monthly costs for psychotropics were BRL $230.30 \pm 428.42$ and BRL $208.51 \pm 354.42$ for the mild and severe/moderate group, respectively.

The average $( \pm \mathrm{SD})$ monthly cost of health service use and mental health interventions (including all medications) were BRL $459.52 \pm 721.43$ and BRL $386.71 \pm 652.05$ for the mild and moderate/severe group, respectively. This difference was not statistically significant. Mean $( \pm$ SD) accommodation costs per resident were BRL $3464 \pm 232.90$ and BRL $3536.26 \pm 269.25$ for the mild and moderate/severe group, respectively.
Table 1 Psychiatric diagnostics, severity of symptoms and sociodemographic profiles $(n=147)$

\begin{tabular}{|c|c|c|}
\hline Characteristic & $n$ & $(\%)$ \\
\hline \multicolumn{3}{|l|}{ Sex } \\
\hline Female & 75 & 51.0 \\
\hline Male & 72 & 49.0 \\
\hline \multicolumn{3}{|l|}{ Education } \\
\hline Illiterate & 30 & 20.4 \\
\hline Primary school I (grade 1-4) & 78 & 53.1 \\
\hline Primary school II (grade 5-8) & 23 & 15.6 \\
\hline High school (grade 9-11) & 12 & 8.2 \\
\hline College & 3 & 2.1 \\
\hline Not stated & 1 & 0.7 \\
\hline \multicolumn{3}{|l|}{ Occupational status } \\
\hline Never worked & 94 & 63.9 \\
\hline Unemployed & 40 & 28.6 \\
\hline Formal work & 1 & 0.7 \\
\hline Retired & 9 & 6.1 \\
\hline Not stated & 3 & 2.0 \\
\hline \multicolumn{3}{|l|}{ Marital status } \\
\hline Single & 119 & 81.0 \\
\hline Married & 12 & 6.8 \\
\hline Widow & 4 & 2.7 \\
\hline Divorced & 7 & 4.8 \\
\hline Not stated & 5 & 3.4 \\
\hline \multicolumn{3}{|l|}{ Psychiatric diagnosis (DSM-IV, MINI) } \\
\hline Psychosis, current & 77 & 52.4 \\
\hline Psychosis, lifetime & 106 & 72.1 \\
\hline Psychosis with mood disorder & 10 & 6.8 \\
\hline Alcohol abuse or dependence, current & 2 & 1.4 \\
\hline Alcohol dependence, lifetime & 11 & 7.5 \\
\hline Drug abuse or dependence, current & 10 & 6.8 \\
\hline Drug dependence, lifetime & 9 & 6.1 \\
\hline Depression, current & 5 & 3.4 \\
\hline Depression, lifetime & 11 & 7.5 \\
\hline Mania, current & 2 & 1.4 \\
\hline Mania, lifetime & 3 & 2.0 \\
\hline Panic disorder, current or lifetime & 1 & 0.7 \\
\hline Agoraphobia, current & 1 & 0.7 \\
\hline GAD, current & 1 & 0.7 \\
\hline Social phobia, current & 1 & 0.7 \\
\hline Antisocial personality disorder & 1 & 0.7 \\
\hline \multicolumn{3}{|c|}{ CGI severity of psychiatric symptoms (scores $1-7$ ) } \\
\hline Normal (score 1) & 3 & 2 \\
\hline Borderline (score 2) & 15 & 10.2 \\
\hline Mild (score 3) & 33 & 22.4 \\
\hline Moderate (score 4) & 28 & 19 \\
\hline Marked (score 5) & 38 & 25.9 \\
\hline Severe (score 6) & 24 & 16.3 \\
\hline Most extreme (score 7) & 6 & 4.1 \\
\hline
\end{tabular}


Table 1 continued

\begin{tabular}{lll}
\hline Characteristic & $n$ & $(\%)$ \\
\hline Residential region & & \\
North & 40 & 27.21 \\
South & 15 & 10.20 \\
East & 24 & 16.32 \\
South-East & 36 & 24.49 \\
Centre-West & 32 & 21.78 \\
\hline
\end{tabular}

CGI Clinical Global Impression, DSM-IV Diagnostic and Statistical Manual of Mental Disorders, 4th edition, $G A D$ generalised anxiety disorder, MINI Mini International Neuropsychiatric Interview

Table 4 shows accommodation and health service costs per resident during the previous month. Unit costs for accommodation were estimated according to July 2011 resource use (Electronic Supplementary Material). Direct monthly health costs per resident ranged from BRL 3200 to BRL 9290 (converted using the Purchasing Power Parity [PPP] exchange rate of US $\$ 1=$ BRL 1.47: US $\$ 2175.00$ and US \$6315.43).

Costs were distributed across the following areas: accommodation/residential service (89.4\%), health services (4.4\%), medication $(6.2 \%)$ and psychosocial treatment $(<0.001 \%)$. Monthly costs per residential service ranged from BRL 26,159.05 to BRL 33,971.91, an average cost per service of BRL 28,380.00. The detailed information regarding the estimation of each cost component and unit costs across different residential services are available in the Electronic Supplementary Material and Razzouk [7].

A linear regression analysis was conducted to assess predictors of accommodation costs (Table 5). Three variables explained $66 \%$ of the variance in monthly accommodation costs per resident: geographic region of the residential service, length of time spent in a psychiatric hospital and length of time living in residential services. A second linear regression model (Table 5) explored the impact of predictors on quality of life. Three variables explained approximately 53\% of the QLS variance: years of education, CGI-S score and ILSS score.

\section{Discussion}

Accommodation costs accounted for $90 \%$ of the direct health costs and were not predicted by resident profiles in the present study. Poor quality of life and independent living skills, severe psychiatric symptoms and social withdrawal were the main characteristics observed among two-thirds of our sample. Furthermore, 95\% of both groups
Table 2 Economic, social and psychosocial resident characteristics $(n=147)$

\begin{tabular}{|c|c|}
\hline Documents & $n(\%)$ \\
\hline Birth certificate & $104(70.7)$ \\
\hline ID (national identity register) & $134(91.2)$ \\
\hline National insurance number & $121(82.3)$ \\
\hline Voter register & $83(56.5)$ \\
\hline \multicolumn{2}{|l|}{ Income (per month) $(\mathrm{BRL})^{\mathrm{a}}$} \\
\hline None & $38(25.9)$ \\
\hline$<251.00$ & $1(0.7)$ \\
\hline $251.00-500.00$ & $7(4.8)$ \\
\hline $501.00-1000.00$ & $98(66.7)$ \\
\hline $1001.00-2000.00$ & $3(2.0)$ \\
\hline \multicolumn{2}{|l|}{ Benefits } \\
\hline None & $45(30.6)$ \\
\hline One or more benefits & $102(69.4)$ \\
\hline Mental health benefits (return home programme) & $22(9.0)$ \\
\hline Social benefits $\left(\mathrm{BPC} / \mathrm{LOAS}^{\mathrm{b}}\right)$ & $87(59.2)$ \\
\hline \multicolumn{2}{|l|}{ Autonomy (ILSS) } \\
\hline Able to manage money (independently) & $46(31.2)$ \\
\hline Able to get transportation (take a bus independently) & $30(20.3)$ \\
\hline Able to perform self-care (hygiene) & $74(50.4)$ \\
\hline \multicolumn{2}{|l|}{ Social behaviour (scores $\geq 3$ ) } \\
\hline Odd communication & $74(50.4)$ \\
\hline Incoherence of speech & $80(54.5)$ \\
\hline Inappropriate social mixing & $85(57.9)$ \\
\hline Poor self-care & $74(50.4)$ \\
\hline \multicolumn{2}{|l|}{ Quality of life: interpersonal relations } \\
\hline Household & $13(8.9)$ \\
\hline Friends & $07(4.9)$ \\
\hline Acquaintances & $07(4.9)$ \\
\hline \multicolumn{2}{|l|}{ Quality of life: social functioning } \\
\hline Social activity & $02(1.4)$ \\
\hline Social network & $06(4.1)$ \\
\hline Social initiative & $04(2.8)$ \\
\hline No social withdrawal & $12(8.2)$ \\
\hline Social and sexual relationship & $03(2.1)$ \\
\hline \multicolumn{2}{|l|}{ Quality of life: intrapsychic foundations } \\
\hline Sense of purpose of life & $09(6.2)$ \\
\hline Motivation & $07(4.8)$ \\
\hline No aimless inactivity & $13(8.9)$ \\
\hline
\end{tabular}

BRL Brazilian Real, ILSS Independent Living Skills Scale, PPP Purchasing Power Parity

${ }^{\mathrm{a}}$ Income was categorised taking into account national wage stratification. Social benefit return was lower than the minimum wage salary. In 2011, the minimum wage for São Paulo was BRL 628.00 (PPP exchange rate US $\$ 1=$ BRL 1.47)

${ }^{\mathrm{b}} \mathrm{A}$ type of social benefit for vulnerable people: Benefício de Prestação Continuada (BPC) regulado pela Lei Orgânica de Assistência Social (LOAS) - continuous benefit conveyance regulated by the Organic Law of Social Welfare 
Table 3 Monthly health service use and costs according to the severity of psychiatric symptoms

\begin{tabular}{|c|c|c|c|c|c|c|}
\hline \multirow[t]{2}{*}{ Health service } & \multicolumn{3}{|c|}{ CGI scores $1-3$ (normal to mild symptoms) $[n=51]$} & \multicolumn{3}{|c|}{ CGI scores 4-7 (moderate to severe symptoms) $[n=96]$} \\
\hline & $n$ & $\begin{array}{l}\text { Mean (SD) service } \\
\text { use frequency in } \\
\text { previous month }\end{array}$ & $\begin{array}{l}\text { Mean (SD) costs in } \\
\text { previous month (BRL) }\end{array}$ & $n$ & $\begin{array}{l}\text { Mean (SD) service } \\
\text { use frequency in } \\
\text { previous month }\end{array}$ & $\begin{array}{l}\text { Mean (SD) costs in } \\
\text { previous month (BRL) }\end{array}$ \\
\hline Psychiatric hospital (days) & 0 & & & 3 & $24(7.9)$ & $1920.00(634.98)$ \\
\hline $\begin{array}{l}\text { Psychiatric unit in general } \\
\text { hospital (days) }\end{array}$ & 0 & & & 1 & 3 & 300 \\
\hline $\begin{array}{l}\text { Non-psychiatric general } \\
\text { hospitalisation (days) }\end{array}$ & 1 & 20 & 2000.00 & 1 & 2 & 200 \\
\hline $\begin{array}{l}\text { Non-psychiatric first aid } \\
\text { service (visits) }\end{array}$ & 7 & 1 & 48.00 & 4 & $1.25(0.25)$ & $60.00(24.00)$ \\
\hline $\begin{array}{l}\text { Non-psychiatric emergency } \\
\text { beds (day) }\end{array}$ & 0 & & & 3 & $10.67(16.74)$ & $1066.67(1674.31)$ \\
\hline $\begin{array}{l}\text { Non-psychiatric emergency } \\
\text { room }(<24 \mathrm{~h})\end{array}$ & 2 & 1 & 48.00 & 6 & $1.17(0.41)$ & $56.00(19.60)$ \\
\hline $\begin{array}{l}\text { Non-psychiatric outpatient } \\
\text { care (visits) }\end{array}$ & 14 & $1.5(0.65)$ & $60.27(26.13)$ & 11 & $1.27(0.47)$ & $51.13(18.76)$ \\
\hline Primary care (20-min visits) & 23 & 1 & $32.8(8.7)$ & 27 & 1 & $35.91(12.28)$ \\
\hline $\begin{array}{l}\text { Centre of psychosocial care } \\
\text { (visits): type II }\end{array}$ & 43 & $5.98(5.6)$ & & 76 & $4.67(4.67)$ & \\
\hline $\begin{array}{l}\text { Centre of psychosocial care } \\
\text { (visits): type III }\end{array}$ & 3 & $3.0(1.73)$ & & 13 & $3.38(3.97)$ & \\
\hline Psychiatrists (30-min visit) & 44 & $1.18(0.65)$ & $65.0(36.12)$ & 87 & $1.07(0.37)$ & $58.79(20.19)$ \\
\hline $\begin{array}{l}\text { Non-psychiatrist doctor (20- } \\
\text { min visits) }\end{array}$ & 17 & $1.29(0.59)$ & $47.36(21.52)$ & 26 & $1.19(0.49)$ & $43.92(18.3)$ \\
\hline $\begin{array}{l}\text { Psychiatric nurse (15-min } \\
\text { visits) }\end{array}$ & 3 & $1.67(0.58)$ & $10.45(3.62)$ & 1 & 2 & 12.54 \\
\hline $\begin{array}{l}\text { Psychologist (90-min group } \\
\text { visits) }\end{array}$ & 11 & $3.91(1.7)$ & $17.2(7.48)$ & 24 & $3.4(1.4)$ & $14.96(6.48)$ \\
\hline $\begin{array}{l}\text { Social worker (60-min } \\
\text { group visits) }\end{array}$ & 2 & $1.5(0.7)$ & $3.12(1.37)$ & 7 & $3(3.4)$ & $6.24(7.10)$ \\
\hline $\begin{array}{l}\text { Occupational therapist (90- } \\
\text { min group visits) }\end{array}$ & 8 & $4.2(2.25)$ & $19.74(10.58)$ & 15 & $4.06(1.73)$ & $19.09(8.13)$ \\
\hline $\begin{array}{l}\text { Physiotherapist (30-min } \\
\text { visits) }\end{array}$ & 1 & 4 & 50 & 1 & 4 & 50 \\
\hline $\begin{array}{l}\text { Workshop technician (60- } \\
\text { min group visits) }\end{array}$ & 13 & $5.75(5.8)$ & $6.38(6.45)$ & 18 & $4.11(4.92)$ & $4.56(5.46)$ \\
\hline
\end{tabular}

$B R L$ Brazilian real

had at least one contact with a CAPS service, typically for a psychiatric visit, and almost $25 \%$ of individuals in the most severe psychiatric group received at least one psychosocial intervention during that period. Although there is no established standard for the periodicity of psychosocial treatment, these practices were not delivered at least once a week, suggesting there was an underutilisation of resources among the present sample [36]. Two potential explanations for this finding are the low adherence to treatment among those with more severe symptoms and greater efforts by mental health teams to treat younger patients at the beginning of their illness. Health service costs (excluding residential costs) were higher in the mild group than in the moderate/severe group, though this difference was not statistically significant. No significant differences were observed regarding the pattern of antipsychotic prescriptions between both groups, suggesting that higher costs for atypical antipsychotics were the main component of health service costs among both groups.

These results have three main implications for mental health policies: resource optimisation, residential costs and strategies for residents' social inclusion. First, our findings are in accordance with other studies reporting accommodation costs ranging between 65 and $95 \%$ of direct health costs $[12,15,35]$, as well as costs being influenced by the size and region of the service. In the present study, two residential services located in the south of São Paulo were the main predictor $(62 \%)$ of costs. Compared with other 
Table 4 Monthly direct health costs per resident $(n=147)$

\begin{tabular}{|c|c|c|c|c|c|}
\hline Health costs & $n$ & $\begin{array}{l}\text { Mean cost per } \\
\text { resident (BRL) }\end{array}$ & $\begin{array}{l}\text { SD } \\
(B R L)\end{array}$ & $\begin{array}{l}\text { Minimum } \\
(\mathrm{BRL})\end{array}$ & $\begin{array}{l}\text { Maximum } \\
\text { (BRL) }\end{array}$ \\
\hline 24-h staffed residential service & 147 & 3511.19 & 258.73 & 3158.02 & 4202.55 \\
\hline Medication use (psychotropic) & 146 & 216.07 & 380.40 & 0 & 1822.50 \\
\hline Medication use (non-psychotropic) & 75 & 24.20 & 158.28 & 0 & 1362.63 \\
\hline Psychiatrist (visits per month: CAPS) & 131 & 54.25 & 31.52 & 0 & 220.00 \\
\hline Psychologist (visits per month: CAPS) & 35 & 3.83 & 7.52 & 0 & 35.2 \\
\hline Occupational therapist (per month: CAPS) & 23 & 3.42 & 8.27 & 0 & 47.00 \\
\hline Social worker (per month: CAPS) & 8 & 0.33 & 1.99 & 0 & 16.64 \\
\hline Psychiatric nurse (per month: CAPS) & 4 & 0.29 & 1.84 & 0 & 12.54 \\
\hline Non-psychiatrist doctor (visits per month) & 43 & 12.94 & 22.98 & 0 & 109.80 \\
\hline CAPS (types II or III) & 140 & 65.22 & 34.06 & 0 & 224.00 \\
\hline Psychiatric hospital (days) & 3 & 24.48 & 220.70 & 0 & 2400.00 \\
\hline Psychiatric bed in general hospital (days) & 1 & 2.04 & 24.74 & 0 & 300.00 \\
\hline General hospital and emergency rooms & 21 & 43.15 & 330.00 & 0 & 3048.00 \\
\hline Primary care (family health programme) & 8 & 1.64 & 6.86 & 0 & 30.18 \\
\hline Primary care (unit of primary care: UBS) & 42 & 10.08 & 17.14 & 0 & 64.30 \\
\hline Outpatient care (other medical specialties) & 11 & 9.53 & 23.19 & 0 & 120.00 \\
\hline Outpatient care (non-medical specialities) & 2 & 0.14 & 1.45 & 0 & 12.50 \\
\hline Ambulance & 4 & 1.88 & 11.33 & 0 & 79.44 \\
\hline $\begin{array}{l}\text { Total package of care: accommodation, mental and healthcare (including } \\
\text { medication, transport and services) }\end{array}$ & 147 & 3923.00 & 733.59 & 3200.00 & 9290.00 \\
\hline
\end{tabular}

BRL Brazilian real, CAPS centre of psychosocial care, $S D$ standard deviation, $U B S$ Unidade básica de saúde

Table 5 Regression analyses

\begin{tabular}{|c|c|c|c|c|c|c|}
\hline Variable & $\begin{array}{l}\beta \\
\text { coefficient }\end{array}$ & $\begin{array}{l}95 \% \text { CI } \\
\text { minimum }\end{array}$ & $\begin{array}{l}95 \% \text { CI } \\
\text { maximum }\end{array}$ & $\begin{array}{l}\text { Standard } \\
\text { error }\end{array}$ & $p$ value & $R^{2}$ \\
\hline \multicolumn{6}{|c|}{ Model 1 dependent variable: monthly accommodation costs per resident (BRL) } & 0.66 \\
\hline Geographic region (ref: north $[n=40]$ ) & & & & & & 0.62 \\
\hline South region $(n=15)$ & 526.23 & 439.11 & 633.36 & 49.13 & $<0.001$ & \\
\hline South-east region $(n=36)$ & 126.77 & 53.07 & 200.46 & 37.27 & $<0.001$ & \\
\hline East region $(n=24)$ & -220.37 & -303.20 & 137.55 & 41.89 & $<0.001$ & \\
\hline $\begin{array}{l}\text { Length of time living in a psychiatric hospital } \\
\text { (months) }\end{array}$ & 0.50 & 0.13 & 0.86 & 0.18 & 0.007 & 0.05 \\
\hline Length of time living in a residential service (months) & -4.34 & -6.99 & -1.69 & 1.34 & 0.001 & 0.07 \\
\hline SBS score & -3.12 & -6.72 & 0.46 & 1.81 & 0.08 & 0.01 \\
\hline CGI-S score & 20.96 & -8.4 & 50.3 & 14.86 & 0.16 & 0.01 \\
\hline ILSS score & -0.15 & -0.87 & 0.56 & 0.36 & 0.67 & 0.01 \\
\hline \multicolumn{6}{|l|}{ Model 2 dependent variable: quality-of-life score (QLS) } & 0.527 \\
\hline Years of education & 0.17 & 0.25 & 1.48 & 0.31 & $<0.01$ & 0.03 \\
\hline CGI-S & -0.53 & -9.97 & -5.20 & 1.21 & $<0.01$ & 0.16 \\
\hline SBS total score & 0.05 & -0.17 & 0.34 & 0.013 & 0.49 & \\
\hline ILSS score & 0.23 & 0.02 & 0.14 & 0.03 & $<0.01$ & 0.34 \\
\hline
\end{tabular}

$B R L$ Brazilian real, CGI-S Clinical Global Impression-Severity Scale, CI confidence interval, ILSS Independent Living Skills Scale, $Q L S$ Quality of Life Scale, SBS Social Behaviour Scale 
regions, costs were higher for human resources, overhead, transport, food, supplies and housing repair (see Electronic Supplementary Material). Since there were no significant differences in residents' profiles across regions, optimisation of resources may be achieved by analysing factors contributing to variation in cost components across services.

The effects of long-term institutionalisation on residential service costs need to be addressed further. The length of time living in a psychiatric hospital was longer and more costly among the moderate/severe group, as well as those over the age of 50 years (see Electronic Supplementary Material). It is well-documented that the last cohort of deinstitutionalised patients had more severe psychiatric symptoms [37]; however, in the present study, they left hospitals during the same period of those with mild symptoms. It is likely that long-term institutionalisation may exert some effects on individuals' autonomy, leading to greater dependence and need for care. In this sense, interventions boosting independent skills are crucial for both groups, regardless of illness severity. Conversely, the longer the time spent living in a residential service, direct health and accommodation costs decreased, reinforcing the need for investigating variable health service use and costs across time. Significant health cost reduction over 3 and 5 years living in a residential service was reported in a study assessing individuals with very severe psychiatric symptoms, revealing improved sociability and resident autonomy and eligibility to be transferred to semistaffed homes [37].

There is a vast literature comparing costs between psychiatric hospitals and residential services, along with potential mechanisms for cost savings. In Brazil, the reimbursement for 1 day in a psychiatric hospital and residential service (per person) in 2011 was BRL 32.00 and BRL 83.00, respectively. Currently, these costs have increased to BRL 100.00 and BRL 125.00, respectively. However, this does not represent all real costs. In the present study, the average annual residential cost per resident was BRL 42,132.00 (BRL 113.00 per day), which is double the annual per capita income in Brazil and 1.6 times the per capita income in São Paulo as of 2011. To put this into perspective for costs in December 2017, the average monthly cost of residential services would be BRL $28,380.00$ (PPP exchange rate: 1.42; US $\$ 19,293.00$ ) to BRL 40,361.41 (inflator factor for São Paulo-FIPE [Economic Research Institute Foundation]: 1.42 according to the Central Bank of Brazil; PPP exchange rate: 2.057; US $\$ 19,621,44$; available on the Organisation for Economic Co-operation and Development [OECD] website [https:// data.oecd.org/conversion/purchasing-power-parities-ppp. $\mathrm{htm}]$ ), or BRL 168.00 per resident per day. This estimation would correspond to 8.9 times the annual per capita income in São Paulo (US \$26,391.00). However, this prediction should be interpreted with caution since we did not apply the exact inflator for each component of costs, and it may not represent all real costs. Nevertheless, public expenditures may not follow inflation, especially during the recent economic recession. The World Health Organization (WHO) [38] has suggested that intervention cost-effectiveness ranges between one- and three-fold the annual per capita income within low- and middle-income countries; however, there is a lack of research exploring the appropriateness of using these rates for evaluating health service costs.

The second implication for mental healthcare policies is related to the relationship between residential costs and resident profiles. Unlike other studies, psychiatric symptom severity was not a predictor of residential costs. One possible explanation for this finding is the fact that patients were transferred to fully staffed homes, regardless of their illness severity, since this was the only modality available in São Paulo. It is reasonable to suppose that the 33\% of individuals with mild symptoms and good autonomy might benefit from partially staffed facilities that would be less costly, as reported in other studies [14]. There is a need to offer variable residential service modalities according to the specific level of support needed [16]. The transition from fully staffed to other accommodation modalities should be planned and evaluated according to the context, budget and users' needs. Other modalities with different sizes, structure and costs might be potentially cost saving, and future evaluations are needed in this regard $[15,16,38]$. Fully staffed residential facilities cannot be regarded as a definitive service for all patients because needs and costs can vary over time. Conversely, some residents living with more autonomy within independent houses may sometimes need to return to a fully staffed home, moving from one service to another in a non-linear manner [16, 40]. Long-term outcomes and pathways among services and costs vary across countries and user profiles [40,41], but there is evidence that some residents do not require fully staffed homes after 6 years living in residential services. Therefore, residential costs should be analysed above and beyond outcomes, allowing flexible adjustments for offering different accommodation modalities according to resident needs [7, 16, 35, 39].

Lastly, one goal of deinstitutionalisation is to promote residents' social inclusion and participation in the community. In this regard, it is important to note that health and non-health community services were underused by the majority of the present sample. As noted earlier, residents received regular psychiatric treatment, with antipsychotic polytherapy, but did not receive a specific package of care for recovery and psychosocial rehabilitation. Also, the high frequency of sluggishness and inactivity in this sample may 
in part be explained by adverse effects of antipsychotic polytherapy and cognitive deficits related to psychotic disorders. Specific interventions, such as cognitive remediation therapy and avoiding antipsychotic polytherapy, may be helpful for improved social and clinical outcomes in this sample [20, 42]. One unexpected finding was the poor quality of life observed in the present sample. This could be presumed by institutionalisation effects not being totally reversed after discharge from a psychiatric hospital. However, the main predictors of poor quality of life were symptom severity and low level of social skills, low selfcare and poor education. Therefore, tailoring a specialised package of care [43] in terms of psychosocial rehabilitation and social inclusion might foster improvement in the quality of life. Services promoting patient's activity and social skills were reported to be associated with better outcomes, greater services effectiveness and lower costs [44]. Despite innumerable free, non-healthcare services available in São Paulo, only 15\% of the sample engaged in activities of leisure, workshops and job training centres. However, this sample was mainly unemployed, poorly educated and with no previous work training. Furthermore, 95\% of the sample displayed social withdrawal and poor social network composition, suggesting that using such services would be beneficial for recovery and improved quality of life [45]. Moreover, $30 \%$ of the sample did not receive welfare benefits or have basic identity registration, which would hinder each citizen's ability to engage in full public welfare opportunities.

\section{Study Strengths and Limitations}

This was the first study in Brazil using a bottom-up approach for assessing the full direct costs among individuals discharged from psychiatric hospitals into residential services. These results could be used as a reference for future residential service planning in the State of São Paulo and for modelling data during economic evaluations.

The present results have some limitations concerning the cross-sectional study design, small sample size, low use of health services, short-term evaluation of costs, lack of information regarding resident profiles during hospital admittance and the types of treatments previously delivered. Additionally, all data related to health service use were obtained from caregivers and notes; it was not possible to check the accuracy of these data, and biased reports cannot be ruled out. Hence, the present results might not generalise to other populations with different characteristics, services and geographic regions. The present sample might also not be fully representative of the entire population of individuals discharged from psychiatric hospitals, as they were the last cohort to be deinstitutionalised in São Paulo and may have presented with more severe symptoms than prior cohorts. However, the present sample had similar characteristics to those remaining at hospitals in the broader State of São Palo reported in the last psychosocial census [19].

\section{Conclusion}

Accommodation costs corresponded to a substantial part of direct health costs and were not predicted by resident profiles. Optimising resources would be possible if other residential modalities with different levels of support are available and tailored according to a resident's needs. The underutilisation of community and mental health services, regardless of resident needs and profiles, suggest the need for further evaluation regarding strategies for promoting psychosocial rehabilitation and social inclusion.

Acknowledgements We thank Aglae Sousa (data collection), Andrea Cardoso (data collection), Monica Kayo (data collection) and Hugo Cogo (statistical analysis support).

\section{Compliance with Ethical Standards}

Funding Funding was addressed exclusively for financing this study and researcher didn't receive any stippend for conducting the study.

Ethical approval The Ethical Committee of the Secretary of Health for the Mayor of São Paulo (no. 140/10) approved this study. The study has been performed in accordance with ethical standards outlined in the Declaration of Helsinki. The study was funded by a public research organisation, Fapesp (Fundação de Amparo à Pesquisa do Estado de São Paulo), Grant number 2009/53286-3.

Informed consent Trained researchers visited each facility and explained the study goals to all residents. All eligible caregivers and residents included in the study provided written informed consent.

Conflict of interest Denise Razzouk declares no conflicts of interest.

Data Availability Statement The author declares that all data supporting the findings of this study are available within the article and its supplementary information file.

Open Access This article is distributed under the terms of the Creative Commons Attribution-NonCommercial 4.0 International License (http://creativecommons.org/licenses/by-nc/4.0/), which permits any noncommercial use, distribution, and reproduction in any medium, provided you give appropriate credit to the original author(s) and the source, provide a link to the Creative Commons license, and indicate if changes were made.

\section{References}

1. Killaspy H. From the asylum to community care: learning from experience. Br Med Bull. 2006;79-80:245-58.

2. Salisbury TT, Killaspy H, King M. The relationship between deinstitutionalization and quality of care in longer-term 
psychiatric and social care facilities in Europe: a cross-sectional study. Eur Psychiatry. 2016;42:95-102.

3. Knapp M, Beecham J, Fenyo A, Hallam A. Community mental health care for former hospital in-patients. Predicting costs from needs and diagnoses. Br J Psychiatry Suppl. 1995;27:10-8.

4. Knapp M, Beecham J, McDaid D, Matosevic T, Smith M. The economic consequences of deinstitutionalisation of mental health services: lessons from a systematic review of European experience. Health Soc Care Commun. 2011;19(2):113-25.

5. Beecham J, Knapp M, McGilloway S, Donnelly M, Kavanagh S, Fenyo A, et al. The cost-effectiveness of community care for adults with learning disabilities leaving the-the long-stay hospital in Northern Ireland. J Intellect Disabil Res. 1997;41(Pt 1):30-41.

6. Killaspy H. Supported accommodation for people with mental health problems. World Psychiatry. 2016;15(1):74-5.

7. Razzouk D. Estimating costs of residential services. In: Razzouk $\mathrm{D}$, editor. Mental health economics: the costs and benefits of psychiatric care. 1st ed. Cham: Springer International Publishing; 2017. p. 253-65.

8. Reeder C, Harris V, Pickles A, Patel A, Cella M, Wykes T. Does change in cognitive function predict change in costs of care for people with a schizophrenia diagnosis following cognitive remediation therapy? Schizophr Bull. 2014;40(6):1472-81.

9. Beecham J, Hallam A, Knapp M, Carpenter J, Cambridge P, Forrester-Jones R, et al. Twelve years on: service use and costs for people with mental health problems who left psychiatric hospital. J Ment Health. 2004;13(4):363-77.

10. Mateus MD, Mari JJ, Delgado PG, Almeida-Filho N, Barrett T, Gerolin J, et al. The mental health system in Brazil: policies and future challenges. Int J Ment Health Syst. 2008;2(1):12.

11. Chisholm D, Knapp MR, Astin J, Lelliott P, Audini B. The mental health residential care study: predicting costs from resident characteristics. Br J Psychiatry. 1997;170:37-42.

12. Amaddeo F, Grigoletti L, de Girolamo G, Picardi A, Santone G. Which factors affect the costs of psychiatric residential care? Findings from the Italian PROGRES study. Acta Psychiatr Scand. 2007;115(2):132-41.

13. Hallam A, Knapp M, Jarbrink K, Netten A, Emerson E, Robertson J, et al. Costs of village community, residential campus and dispersed housing provision for people with intellectual disability. J Intellect Disabil Res. 2002;46(Pt 5):394-404.

14. Felce D, Perry J, Romeo R, Robertson J, Meek A, Emerson E, et al. Outcomes and costs of community living: semi-independent living and fully staffed group homes. Am J Ment Retard. 2008;113(2):87-101.

15. Emerson E, Robertson J, Gregory N, Hatton C, Kessissoglou S, Hallam A, et al. Quality and costs of supported living residences and group homes in the United Kingdom. Am J Ment Retard. 2001;106(5):401-15.

16. Killaspy H, Priebe S, Bremmer S, McCrone P, Dawling S, Harrison I, et al. Quality of life, autonomy, satisfaction, and costs associated with mental health supported accommodation services in England: a national survey. Lancet Psychiatry. 2016;3(12):1129-37.

17. Neri G, Guzzetta F, Pazzi L, Bignami R, Picardi A, Girolamo G. How does the residential care system change? A longitudinal survey in a large region of Italy. Commun Ment Health J. 2011;47:201-8.

18. World Health Organization, Gulbenkian Global Mental Health Platform. Innovation in deinstitutionalization: a WHO expert survey. Geneva, World Health Organization, 2014. http://www. who.int/iris/handle/10665/112829. Accessed 25 Sept 2017.

19. Silva A, Pitta A, Covre E, Souza J, Oliveira M, Nicácio M, et al. Desafios para a desinstitucionalização: Censo psicossocial dos moradores em hospitais psiquiátricos do Estado de São Paulo. Sao Paulo: FUNDAP Secretaria do Estado de São Paulo; 2008.
20. Razzouk D, Kayo M, Sousa A, Gregorio G, Cogo-Moreira H, Cardoso AA, et al. The impact of antipsychotic polytherapy costs in the public health care in Sao Paulo, Brazil. PLoS ONE. 2015;10(4):e0124791. https://doi.org/10.1371/journal.pone. 0124791.

21. Amorim P. Mini International Neuropsychiatric Interview (MINI): validation of a short structured diagnostic psychiatric interview. Rev Bras Psiquiatr. 2000;22(3):106-15.

22. Sheehan D. The Mini International Neuropsychiatric Interview (MINI): the development and validation of a structured diagnostic psychiatric interview for DSM-IV and ICD-10. J Clin Psychiatry. 1998;59(suppl 20):22-33.

23. Haro JM, Kamath SA, Novick D, Rele K, Fargas A, Rodriguez MJ, et al. The Clinical Global Impression-Schizophrenia scale: a simple instrument to measure the diversity of symptoms present in schizophrenia. Acta Psychiatr Scand Suppl. 2013;416:16-23.

24. Lima M, Soares B, Paoliello G, Vieira R, Martins C, MotaNeto J, et al. The Portuguese version of the Clinical Global ImpressionSchizophrenia Scale: validation study. Rev Bras Psiquiatr. 2007;29(3):246-9.

25. Cardoso CS, Bandeira M, Caiaffa WT, Fonseca JOP. Quality of life scale for patients with schizophrenia, Brazilian version: transcultural adaptation to Brazil [Escala de qualidade de vida para pacientes com esquizofrenia QLSBR: Adaptação transcultural para o Brasil]. J Bras Psiquiatr. 2002;51(1):31-8.

26. Heinrichs DW, Hanlon TE, Carpenter WT Jr. The Quality of Life Scale: an instrument for rating the schizophrenic deficit syndrome. Schizophr Bull. 1984;10(3):388-98.

27. Wykes T, Sturt E. The measurement of social behaviour in psychiatric patients: an assessment of the reliability and validity of the SBS schedule. Br J Psychiatry. 1986;148:1-11.

28. Wallace C, Liberman RP, Tauber R, Wallace J. The independent living skills survey: a comprehensive measure of the community functioning of severely and persistently mentally ill individuals. Schizophr Bull. 2000;26(3):632-58.

29. Bandeira M, Lima LA, Gonçalves S. Qualidades psicométricas no papel da Escala de Habilidades de Vida Independente de pacientes psiquiátricos (ILSS-BR). Rev Psiq Clín. 2003;30(4):121-5.

30. Lima LA, Gonçalves S, Pereira BB, Lovisi G. The measurement of social disablement and assessment of psychometric properties of the social behaviour schedule (SBS-BR) in 881 Brazilian longstay psychiatric patients. Int J Soc Psychiatry. 2006;52(2):101-9.

31. Chisholm D, Knapp M, Amaddeo F, Gaite L, Winjgaarden B. Client Sociodemographic Service Receipt Inventory European version: development of one instrument for international research. Br J Psychiatry. 2000;177(39):s28-33.

32. Sousa A, Cardoso A, Oliveira G, Mari J, Razzouk D. Standardized tool for measurement of health services costs and utilization in a sample with mental disorders: translation, cultural adaptation and interrater reliability of the Client Sociodemographic and Service Receipt Inventory Brazilian Version. Value Health Reg Issues. 2013;16:696.

33. Sousa A, Razzouk D. Economic Data Collection: Instruments for measuring health service use and direct health costs- the bottomup approach. In: Razzouk D, editor. Mental health economics: the costs and benefits of psychiatric care. 1st ed. Cham: Springer International Publishing; 2017. p. 215-23.

34. BRAZIL Ministério da Saude. Medicine database prices [Banco de Preços de Medicamentos]. 2017. http://portalsaude.saude.gov. br/. Accessed 30 July 2011.

35. Knapp M, Chisholm D, Astin J, Lelliott P, Audini B. The cost consequences of changing the hospital-community balance: the mental health residential care study. Psychol Med. 1997;27(3):681-92. 
36. IOM (Institute of Medicine). Psychosocial interventions for mental and substance use disorders: A framework for establishing evidence-based standards. Washington, DC: The National Academies Press; 2015. http://www.nap.edu. Accessed 18 Sept 2015.

37. Leff J, Trieman N, Knapp M, Hallam A. The TAPS project: a report on 13 years of research, 1985-1998. Psychiatr Bull. 2000;24:165-8.

38. Robinson L, Hammit J, Chang A, Resh S. Understanding and improving the one and three times GDP per capita cost-effectiveness thresholds. Health Policy Plan. 2016;32(1):141-5.

39. Felce D. Community living for adults with intellectual disabilities: unravelling the cost-effectiveness discourse. J Policy Pract Intellect Disabil. 2016;14(3):187-97.

40. Trieman N, Smith H, Kendal R, Leff J. The TAPS Project 41: Homes for life? Residential stability five years after hospital discharge. Commun Ment Health J. 1998;34(4):408-17.

41. Hobbs C, Newton L, Tennant C, Rosen A, Tribe K. Deinstitutionalization for long-term mental illness: a 6-year evaluation. Aust N Z J Psychiatry. 2002;36:60-6.
42. Elie D, Poirier M, Chianetta J, Durand M, Gregoire C, Grignon S. Cognitive effects of antipsychotic dosage and polypharmacy: a study with the BACS in patients with schizophrenia and schizoaffective disorder. J Psychopharmacol. 2010;24(7):1037-44.

43. Mari J, Razzouk D, Rangaswamy T, Eaton J, Thornicroft G. Packages of care for schizophrenia in low- and middle-income countries. PLoS Med. 2009;6(10):e1000165.

44. Killaspy H, Martson L, Green N, Harrison I, Lean M, Holloway F, et al. Clinical outcomes and costs for people with complex psychosis; a naturalistic prospective cohort study of mental health rehabilitation service users in England. BMC Psychiatry. 2016;16:9. https://doi.org/10.1186/s12888-016-0797-6.

45. Thornicroft G, Deb T, Henderson C. Community mental health care worldwide: current status and further developments. World Psychiatry. 2016;15(3):276-86. 